\title{
The Effect of Virtual Team Membership Change on Social Identity Development: A Case from Higher Education in Norway
}

\author{
Karen Stendal \\ University College of Southeast Norway \\ karen.stendal@hbv.no
}

\author{
Robert M. Fuller \\ University of Tennessee, USA \\ rfuller2@utk.edu
}

\begin{abstract}
This research attempts to address the question, what factors may influence the perceptions and development of a group social identity on a new virtual team? Of particular interest are prior experiences with virtual team environments, experience with virtual team technology, and other organizational and contextual factors that may be relevant. This research makes use of a natural field experiment and qualitative study on two university colleges that make use of virtual teams and communication. One university college had previously undergone a merger while the other had not. The findings indicate that the previous merger for the one university college still plays a part in how much the employees feel like one unit and perceive their performance and conflict. There is a need to focus on training of virtual team members to ensure appropriate utilization of the technology to enable social identity development.
\end{abstract}

\section{Introduction}

Organizations have increasingly implemented various forms of computer-mediated interacting teams as it allows for flexibility and reduced costs when connecting experts separated by distance. Virtual teams, groups of dispersed individuals who rely on communication and information technologies are an important organizational form for supporting organizational activities that require the skills and knowledge of experts separated by distance and/or time [1]. Given their growing importance in organizations, research has focused on understanding those factors that support these teams and how to ensure that these teams generate the needed performance and affect in order to support organizational goals and objectives [2].

Often a nuisance in experimental virtual teams, but a real occurrence in actual virtual teams, team member turnover and replacement is a concern for the impact it has on the performance and affect in virtual teams [3, 4]. Organizations hope for and expect similar and potentially improved performance, however, research has found that the addition of new members into virtual teams can create friction in the interactions between "old" and "new" members. It is likely that performance suffers without certain interventions that remind team members of the need to interact in certain ways to ensure useful exchange and to embrace new member contributions [3-5].

An interesting wrinkle to this concern of changing virtual team membership is the fact that it is likely that as organizations form and reform virtual teams, new members on these teams potentially have prior experiences with virtual teams in other contexts. As a result, it is not clear how these prior experiences on virtual teams in other contexts may influence the manner in which new virtual teams accept and incorporate new virtual team members. In this context, we are particularly interested in how the existing social identity of a virtual team may facilitate or impede the inclusion of new team members into the virtual team social identity. Social identity is important as it defines how individuals perceive their own group, relative to others and other groups [6]. Given the nuances of the virtual environment, it may be that new members to a virtual team, particularly if they have prior experiences in a virtual environment, may be more or less likely to be quickly incorporated into a virtual team. This may depend on prior experience facilitating entry into the team, or if the virtual environment emphasizes the outgroup nature of the new team member, slowing their acceptance by the group.

This research attempts to address the question, what factors improve or hinder the acceptance of new virtual team members onto an existing virtual team? Of particular interest are prior experiences with virtual team environments, experience with virtual team technology, and other organizational factors that may be relevant. This research makes use of a natural field experiment in which two university colleges that make use of virtual teams and information and communication technologies merge. Through the use 
of both quantitative and qualitative data collection strategies, we collect data to triangulate on and understand the factors that influence affect and performance in virtual teams with changing membership. Research in this area has examined how team membership changes impact virtual team performance. This research extends this research to determine how and for how long these membership changes influence virtual team outcomes. The longitudinal nature of this research allows for a better understanding of not only the factors influencing performance when virtual team membership changes, but allows us to understand when it changes and the durability of new perceptions of interaction and performance levels after a change.

\section{Related Literature}

To understand the changes in virtual team membership on virtual team outcomes, we rely on social identity theory. Social identity theory proposes that when developing social identity, group members try to differentiate their own groups from relevant comparison groups and any threats to diminish this differentiation generate attempts to restore the differentiation between groups [7,8]. Perceptions of distinctiveness between groups is a key element that distinguishes the members' group relative to groups the member compares to. Individuals will typically attend to information that continues to support differences between groups [9] to maintain the social identity of the group. An individual's social identity is socially derived through characteristics of the group he/she is a member.

Group distinctiveness is defined as the perceived difference between a member's group and another group to whom the member's group is being compared [10]. Distinctiveness is determined by three main factors, degree of similarity between groups, the physical distance between groups, and the situational salience between groups [7].

Research has shown that the sharing of similar characteristics, traits, or beliefs such that the perception of sameness between groups increases, has the effect of breaking down differences, and weakening perceptions of ingroup and outgroup distinctions. [11] find that cooperation and contact can reduce perceived intergroup differences and bias, reducing group distinctiveness as information is passed between groups. The result can be a new group consisting of members from both prior groups.

In computer-mediated environments, two theories attempt to explain how the development of group categorizations or personal and group identity is attained. The social identity model of deindividuation effects (SIDE model) proposes that in computermediated communication environments, individuals behave in a more de-individualized manner due to the relative anonymity provided in this environment (compared to face-to-face environments) [6]. As a result of the lessened salience of individual identity, individuals have a tendency to identify with the group identity that is experienced by them. As anonymity is greater (e.g., no cues supporting voice or facial and visibility, the use of aliases instead of names), individuals have a tendency to identify with the socially created group identity. As group identity is more noticeable than individual identity in these environments, individual identity is replaced by group identity. Individuals categorize themselves into the more salient group, enhancing ingroup affiliation and identity.

Social information processing theory [12], focuses on interpersonal exchanges of information and proposes that computer-mediated communication environments can convey social relational information such that relationships can develop and grow in this environment. During information exchange, individuals can selectively promote and attend to cues in the information to develop stronger relational ties despite missing certain informational cues such as appearance and voice. The limitation of the constrained communication channel serves to highlight selected cues and delays the process of relational development, but does not stop it.

For the development of social identity, SIDE and SIP both suggest similar outcomes, but via alternative processes. SIDE suggests that individuals develop a social identity based on the group in environments were cues that represent individual identity are lessened. This makes individual identity more like the group identity due to its salience. SIP suggests that through the slower exchange of adapted and perceived relevant social information, individuals can develop perceptions of others' social identity such that they are perceived as similar.

Taken together, both SIP and SIDE suggest similar outcomes as a result of a merging of virtual team members. Given the time needed for virtual team members to learn about each other and the expectations for interaction and performance [13]. It is expected that recently merged virtual teams, that is virtual teams where new team members have been added, may not have had ample time to learn and acclimate to rules of interaction, would have a lower level of shared social identity related perceptions and greater levels of conflict. Perceptions of social identity, similarity of views of the social context in which they work, and different levels of perception on the purpose of the work have been shown to be 
slow to develop in virtual environments [14]. Similarly, teams with different perceptions of identity, purpose and context have been shown to have greater levels of conflict [15]. As a result, we hypothesize that:

H1: Virtual teams that have recent new membership changes (merger) will experience greater differences in a) shared identity and b) task and c) interpersonal conflict and perceive lower levels of d) team effectiveness than teams that have not had recent new membership changes.

Although differences have been suggested by research, it has also been shown that to the degree that individuals perceive similarities between themselves and virtual team members, then higher levels of shared perceptions could exist. These similarities may be due to contexts where individuals perceive similarities in each other physically and in their situations they find themselves in [11]. To the degree that individuals share in similar professional or even national culture, these similarities should result in similar perceptions with virtual team members $[16,17]$. As a result, we hypothesize that:

H2: Virtual teams with recent membership changes (merged) and with similar cultural or professional affiliations will perceive similar levels of a) shared leadership, b) purpose and c) context as teams that have not had recent membership changes.

\section{Case}

In 2007, the Norwegian government appointed a work-group to evaluate the structure of Norwegian Higher Education. The result from this evaluation was a plan for a new structure in Norwegian Higher Education with fewer and larger entities [18]. In 2014, the Norwegian government requested all Norwegian universities and university colleges to explore the possibility for mergers.

Starting on 01/01/16 multiple mergers within the Norwegian higher education sector were conducted. One of these mergers is the context of our study. The merger studied includes two Norwegian University Colleges (VO1 and VO2) who are similar in size. One of the two merging university colleges (VO1) already went through a merger in 01/01/14, and moved towards the second merger within the first year.

VO1 consisted of four campuses and already had cross-campus faculties, for example, the Business School and faculty of Social Sciences had staff of all four campuses. Although, VO1 also had single- campus departments. VO2 also consisted of four campuses; however, their faculties were for the most part single-campus entities.

In a Norwegian context, the merged University College is a large institution in higher education. After the merger the new University College includes:

- $\quad$ Eight Campuses

- Approximately 1500 employees

- Approximately 17000 students

The final organization of the new University College has not been decided at this point. Which means that for all instances purposes, the two original organizations are still in effect, with the exception of one joint vice-chancellor and board.

One important issue to consider when doing research in Norway is the Norwegian Model, which is a unique cultural aspect to the Norwegian context. The Norwegian Model often refers to the establishment of a peculiar corporative political culture and an economic system in Norway [19].

"The Norwegian model ... sought to emphasize welfare, social security, and full employment through negotiations between the state and the business sector." [19].

The Norwegian Model has fostered a climate for compromise and negotiations [19]. Business in Norway is considered to be one of many institutions functioning in society, and is not always seen as the most important, business has often been eyed with skepticism [19]. The Norwegian political system, based on corporatism, dialog, and social democratic government, has given trade unions sufficient influence to limit work place conflicts. Cooperation, consensus, participation, and power sharing have been important keywords, and the model has given employees huge influence [19]. While relations have been strained at times, an underlying understanding of shared interests has prevailed in many Norwegian companies [19].

As a result, these two organizations, VO1 and VO2 represent a relevant case to examine the differences between organizations that have undergone mergers, particularly of individuals on virtual teams. Both make use of virtual teams given the distributed nature of their academic departments whose members work together. VO1, having recently undergone a merger in 2014, provides a context to collect data from individuals who have experienced changes in their virtual team membership while VO2 has no such broad change in virtual team membership over the time period of interest. 


\section{Research Method}

This study uses a mixed method approach to examine the use of communication technology in a multi-campus higher education merger. A mixed method approach uses both qualitative and quantitative research techniques to explore a topic [20]. Mixed methods research can be defined "as the class of research where the researcher mixes or combines quantitative and qualitative research techniques, methods, approaches, concepts or language into a single study" [21]. Mixed method is especially important in exploratory and explanatory studies and when knowledge is limited [22]. Mixed method research provides a wider and more complete understanding of the phenomenon, increase the validity of the data and the findings [22]. Figure 1 illustrates the mixed method approach used in this research.

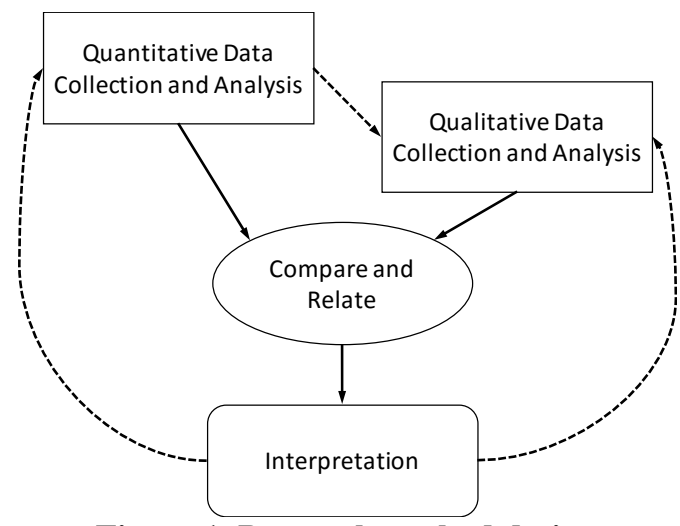

Figure 1. Research method design

\subsection{Quantitative portion of this research}

A natural field experiment provided the data for the quantitative portion of this research. The primary factor, location, was at two levels, naturally determined by the originating location of the participants, either VO1 of VO2. Survey was the primary method of quantitative data collection.

\section{Participants}

Participants were recruited from both VO1 and $\mathrm{VO} 2$ reflecting the two academic virtual organizations prior to the merger. 130 individuals participated, 65 from VO1 and 65 from VO2. Due to IRB requirements, identifying information could not be collected, but demographic information indicated that the groups did not differ in terms of average years in position $(6.7,8.2)$, average years of work experience $(23.3,23.0)$, and average education level $(7.7,7.5)$ for both VO1 and VO2, respectively.

A survey was utilized to collect data from respondents for our dependent variable measures. Six weeks prior to the official announcement of the merger of the two locations, an email with link to the survey was sent out to a sample of participants at both locations. Reminder emails were sent one week and two weeks later. The email contained information about participation in the research as well as a link to the survey, housed at the Qualtrics site of university of the second author.

\section{Dependent Variables}

The dependent variables of interest are shared identity, and team effectiveness, as well as two measures of conflict, interpersonal and task conflict. All perceptual items were measured using 7-point Likert scales with values ranging 1 (Strongly Disagree) to 7 (Strongly Agree). Descriptive statistics for the dependent variables by VO group are presented in Table 1. Correlations between the constructs are shown in Table 2

Table 1. Dependent variable means (std. dev.)

\begin{tabular}{lcc} 
& \multicolumn{2}{c}{ Mean (SD) } \\
Dependent Variable & VO 1 & VO 2 \\
\hline Shared Identity & $5.37(1.47)$ & $5.77(0.95)$ \\
Shared Leadership & $4.41(1.51)$ & $4.48(1.30)$ \\
Shared Purpose & $5.16(1.49)$ & $5.33(1.17)$ \\
Shared Context & $4.24(1.49)$ & $4.10(1.18)$ \\
Team Effectiveness & $4.94(1.42)$ & $5.35(1.11)$ \\
Interpersonal Conflict & $3.18(1.60)$ & $2.73(1.51)$ \\
Task Conflict & $3.34(1.41)$ & $2.91(1.32)$ \\
\hline $\mathrm{N}$ & 63 & 62 \\
\hline
\end{tabular}

Shared identity is defined as the degree to which individuals feel a psychological tie between themselves and others in their relevant work environment. This variable was measured using six items adapted from [15] (alpha $=0.923)$. Shared leadership is defined as the process performed by individuals in work groups in which the objective is to lead one another to the achievement of group goals [23]. This variable was measured using seven items adapted from [24] (alpha $=0.952)$. Shared purpose is defined as the perception that members of a team are similar in their understanding of their team's objectives. This variable was measured using three items from [25] $($ alpha $=0.882)$. Shared context is defined as the perception that members of a team have access to the same team environmental elements such as information, tools, processes, and cultures. 
This variable was measured using four items adapted from [26] (alpha $=0.845)$. Team effectiveness is defined as the assessment of the individual's relevant workgroup in terms of its ability to be successful in the activities needed for performance (use of member skills, coordination, generating ideas, etc.). This variable was measured using four items adapted from [27] (alpha $=0.926)$. Interpersonal conflict is defined as conflict arising from interpersonal differences and incompatibilities when working together [15]. This variable was measured using six items adapted from [26] (alpha $=0.947$. Task conflict is defined as discord over differences between team members regarding the work being done [26]. This variable was measured using four items adapted from [26] $($ alpha $=0.887)$.

Table 2. Dependent variable correlations

\begin{tabular}{|c|c|c|c|c|c|c|c|c|}
\hline \# & Variable & 1 & 2 & 3 & 4 & 5 & 6 & 7 \\
\hline 1 & Shared ID & 1 & & & & & & \\
\hline 2 & Shared Lead & $.646^{* *}$ & 1 & & & & & \\
\hline 3 & Shared Purp & $.514 * *$ & $.514 * *$ & 1 & & & & \\
\hline 4 & Shared Cont & $.501 * *$ & $.580 * *$ & $.403^{* *}$ & 1 & & & \\
\hline 5 & Team Effect & $.695 * *$ & $.647 * *$ & $.524 * *$ &. $.545^{* *}$ & 1 & & \\
\hline 6 & Interp Confl & $.594 * *$ & $.486 * *$ & $.293 * *$ & $.590 * *$ & $.536^{* *}$ & 1 & \\
\hline 7 & Task Confl & $.509 * *$ & $.456 * *$ & $.337 * *$ & $.619 * *$ & $.563^{* *}$ & $.667 * *$ & 1 \\
\hline
\end{tabular}

\subsection{Qualitative portion of the research}

The qualitative section of the data collection consists of interviews with faculty and staff, documents (e.g. website, online data, public meeting documents, and government documents), observation, meeting reports, and informal conversations.

Recruitment of participants for interviews were done by emailing faculty at different campuses. The goal is to interview people from all eight campuses, however, this is an ongoing process. The interviews will continue until there is no new data emerging from the interviews. Sampling is done by the snowball approach [28]. Each participant is asked to name other possible participants that they think could contribute to the process, in turn the possible participants are contacted by the researcher to ask for their participation in the research [28]. Snowball sampling is one of the most common sampling techniques applied within various social sciences disciplines [28].

The interviews were conducted as semi-structured in-depth interviews. Some of the initial findings guided the interviews from the survey data. The aim of the interviews were to understand the preferred meeting method for team meetings.

In this initial qualitative data collection were eight employees, five participants from VO1 and three participants from VO2. The interviews were conducted on campus of the participants in MarchMay 2016. Participants in this initial interview round consisted of five individuals from VO1 and three from VO2. Three of the participants from VO1 comes from departments organized as a multi, the remaining five from a single campus organization. The qualitative data analysis is a continuous process with no specific starting point [29].

Through the data collection period, there was some data analysis performed simultaneously, which guided the ensuing data collection. The data has been examined using content analysis. Content analysis is a well-known and used mode of analysis of qualitative data. Patton [29] stated: "Content analysis is used to refer to any qualitative data reduction and sense-making effort that takes a volume of qualitative material and attempts to identify core consistencies and meanings" (p. 453).

\subsubsection{Validation and limitations}

Triangulation methods were required and applied to validate this research. Patton [29] stated there are four basic methods of triangulation to verify and validate qualitative research, (1) methods triangulation, (2) triangulation of sources, (3) analyst triangulation, and (4) theory/perspective triangulation.

Triangulation of sources were used through crosschecking the consistency of information derived at different times and different means, as described by Patton [29].

\section{Results}

Our research question seeks to understand the difference in virtual teams due to recent changes in membership. Given the quantitative and qualitative approaches followed to answer the question, both sets of findings are explained below.

\subsection{Quantitative Findings}

The differences between groups were tested using analysis of covariance (ANCOVA) which allows us to compare differences in our quantitative dependent variables (shared perceptions of identity, leadership, and conflict) on the basis of our categorical independent variable, location. Given the potential influence of differences in individual 
perceptions of self-efficacy, individualism (or selfreliance) and disposition to trust on our dependent variables, these constructs were measured and used as a covariate during the analysis. Table 3 provides the results of the analysis.

Table 3. ANCOVA results

\begin{tabular}{llccccc} 
Ind & & & & & \\
Var & Dep Var & SS & $d f$ & MS & F & Sig. \\
\hline Change & $\begin{array}{l}\text { Shared } \\
\text { ID }\end{array}$ & 5.03 & 1 & 5.026 & 3.714 & $\mathbf{0 . 0 5 6}$ \\
& $\begin{array}{l}\text { Shared } \\
\text { Lead }\end{array}$ & 0.10 & 1 & 0.097 & 0.054 & 0.817 \\
& $\begin{array}{l}\text { Shared } \\
\text { Purp }\end{array}$ & 1.05 & 1 & 1.05 & 0.582 & 0.447 \\
& $\begin{array}{l}\text { Shared } \\
\text { Cont }\end{array}$ & 0.80 & 1 & 0.795 & 0.464 & 0.497 \\
& $\begin{array}{l}\text { Team } \\
\text { Effect }\end{array}$ & 4.97 & 1 & 4.97 & 3.285 & $\mathbf{0 . 0 7 2}$ \\
& $\begin{array}{l}\text { Interp } \\
\text { Confl }\end{array}$ & 6.96 & 1 & 6.955 & 3.178 & $\mathbf{0 . 0 7 7}$ \\
& $\begin{array}{l}\text { Task } \\
\text { Confl }\end{array}$ & 6.16 & 1 & 6.161 & 3.541 & $\mathbf{0 . 0 6 2}$ \\
\hline
\end{tabular}

\subsubsection{Differences in Perceptions of Identity, Conflict, and Performance}

H1 hypothesized differences between virtual teams with recent membership change and teams without changes as related to perceptions of identity, conflict, and performance. The results of the ANCOVA indicate that a significant difference was found in terms of the shared identity $(\mathrm{F}=3.714, \mathrm{p}=$ 0.056), team effectiveness $(\mathrm{F}=3.285, \mathrm{p}=0.072)$, interpersonal conflict $(\mathrm{F}=3.178, \mathrm{p}=0.077)$ and task conflict $(\mathrm{F}=3.541, \mathrm{p}=0.062)$. Table 1 shows that for these constructs, the values for the unchanging teams was higher than for teams with membership changes, providing support for $\mathrm{H} 1$ (a,b,c,d). Teams with recent membership changes had lower shared identity and higher levels of task and interpersonal conflict, and lower perceptions of effectiveness.

\subsubsection{Similarities in Perceptions of Purpose, Context, and Leadership}

H2 hypothesized that there would not be differences between virtual teams with recent membership change and teams without change as related to perceptions in leadership, purpose, and context. The results of the ANCOVA in Table 3 provides support for this hypothesis in that the differences between the constructs were not significantly different. Given the similar nationality for the respondents, and similar job and training, these results are in line with our predictions. As a result, $\mathrm{H} 2(\mathrm{a}, \mathrm{b}, \mathrm{c})$ is supported.

\subsection{Qualitative Findings}

Table 4 illustrates the main finding from the initial interviews with the 8 participants. These interviews show there is different levels of experience in using technology. All participants report they are familiar with using email as a communication channel. They all feel comfortable with this form of communication; although some report, they may use email in situations where other communication channels may be more beneficial.

Five of the participants prefer physical meetings. They see these meetings as more beneficial in the sense of getting to know each other. They point out the informal conversations during coffee breaks, lunch and after the meeting as important factors to get to know each other. This was also mentioned by an associate professor located in VO1, although, she prefers computer mediated meetings due to less traveling, she acknowledges the informal conversations surrounding physical meetings as important. She even comments it is during these meetings the decisions are made, due to the informal conversations during breaks or outside of the meeting room.

Three of the participants would prefer there to be more computer-mediated meetings. They recognize that physical meetings are richer, however, they feel that time spent traveling among campuses is an unnecessary use of resources. The participants that prefer physical meetings also recognize the importance of saving travel time and resources. They also think that computer-mediated meetings are more efficient. Those who participate in computermediated meetings seem to be more focused and have allocated a certain time for the task. However, one participants noted that decisions tend to be put off to a physical meeting.

Where the discussion is conducted in a computermediated meeting, the conclusion of the discussion is put off until there is a physical meeting. Two of the participants expressed a need for good meeting management to make sure these meetings are productive and deliver the expected outcome. 
Table 4. Findings From Qualitative Interviews

\begin{tabular}{|c|c|c|c|c|}
\hline Participants & $\begin{array}{l}\text { Experience with } \\
\text { comm. tech. }\end{array}$ & Face-to-face & $\begin{array}{c}\text { Skype for } \\
\text { business, video }\end{array}$ & Other comments \\
\hline $\begin{array}{l}\text { Associate } \\
\text { Professor, } \\
\text { VO1 }\end{array}$ & $\begin{array}{l}\text { Email good, } \\
\text { skype ok, video } \\
\text { conference not } \\
\text { good }\end{array}$ & $\begin{array}{l}\text { Informal } \\
\text { conversation, } \\
\text { meetings may drag } \\
\text { out, not good use of } \\
\text { resources, mostly } \\
\text { used in the dept. }\end{array}$ & $\begin{array}{l}\text { Best liked, saves } \\
\text { travel time, more } \\
\text { focused, outcome }\end{array}$ & $\begin{array}{l}\text { Better before } \mathrm{HBV} \text {, online } \\
\text { meetings were easier to } \\
\text { arrange, points out method } \\
\text { depends on the goal of the } \\
\text { meeting }\end{array}$ \\
\hline $\begin{array}{l}\text { Assistant } \\
\text { Professor, } \\
\text { VO1 }\end{array}$ & $\begin{array}{l}\text { Email good, } \\
\text { skype ok, video } \\
\text { conference not } \\
\text { good }\end{array}$ & $\begin{array}{l}\text { Best liked, informal } \\
\text { conversation, } \\
\text { important to get to } \\
\text { know each other }\end{array}$ & $\begin{array}{l}\text { Saves travel time, } \\
\text { more focused, } \\
\text { loose something, }\end{array}$ & $\begin{array}{l}\text { Does not replace } \mathrm{f}-\mathrm{t}-\mathrm{f} \\
\text { meetings, does not want too } \\
\text { much of it }\end{array}$ \\
\hline $\begin{array}{l}\text { Professor, } \\
\text { VO1 }\end{array}$ & $\begin{array}{l}\text { Email good, } \\
\text { skype ok, video } \\
\text { conference not } \\
\text { good }\end{array}$ & $\begin{array}{l}\text { Best liked, informal } \\
\text { conversation, } \\
\text { important to get to } \\
\text { know each other }\end{array}$ & $\begin{array}{l}\text { Focused, saves } \\
\text { travel time, } \\
\text { decisions put off } \\
\text { until f-t-f meetings }\end{array}$ & $\begin{array}{l}\text { Wants more training, more } \\
\text { rooms where people in the } \\
\text { same campus can sit together } \\
\text { during online meetings }\end{array}$ \\
\hline $\begin{array}{l}\text { Associate } \\
\text { Professor, } \\
\text { VO1 }\end{array}$ & Very good & $\begin{array}{l}\text { Important tool to get } \\
\text { to know each other, }\end{array}$ & $\begin{array}{l}\text { Best liked, does } \\
\text { not think anything } \\
\text { is lost by using } \\
\text { technology for } \\
\text { meetings }\end{array}$ & $\begin{array}{l}\text { Should be used as much as } \\
\text { possible }\end{array}$ \\
\hline $\begin{array}{l}\text { Associate } \\
\text { Professor, } \\
\text { VO1 }\end{array}$ & Very good & $\begin{array}{c}\text { Mostly used, } \\
\text { department co-located } \\
\text { at this point }\end{array}$ & $\begin{array}{l}\text { Have extensive } \\
\text { experience using } \\
\text { technology for } \\
\text { external meetings }\end{array}$ & $\begin{array}{l}\text { Expects the rate of online } \\
\text { meetings to increase with the } \\
\text { new merger, will be located } \\
\text { in two campuses }\end{array}$ \\
\hline $\begin{array}{l}\text { Associate } \\
\text { Professor, } \\
\text { VO2 }\end{array}$ & $\begin{array}{c}\text { Email good, } \\
\text { skype ok, video } \\
\text { conference not } \\
\text { good } \\
\end{array}$ & $\begin{array}{l}\text { Mostly used, } \\
\text { department co-located } \\
\text { at this point }\end{array}$ & $\begin{array}{l}\text { Saves travel time, } \\
\text { more focused, } \\
\text { loose something }\end{array}$ & $\begin{array}{l}\text { Wants more training, more } \\
\text { rooms where people in the } \\
\text { same campus can sit together } \\
\text { during online meetings }\end{array}$ \\
\hline $\begin{array}{l}\text { Associate } \\
\text { Professor, } \\
\text { VO2 }\end{array}$ & $\begin{array}{l}\text { Email good, } \\
\text { skype good, video } \\
\text { conference not } \\
\text { good }\end{array}$ & $\begin{array}{c}\text { Mostly used, } \\
\text { department co-located } \\
\text { at this point }\end{array}$ & $\begin{array}{l}\text { Uses Skype for } \\
\text { external meetings }\end{array}$ & $\begin{array}{l}\text { Do not see his patterns } \\
\text { change, due to his field }\end{array}$ \\
\hline $\begin{array}{l}\mathrm{PhD} \\
\text { Candidate, } \\
\text { VO2 }\end{array}$ & $\begin{array}{l}\text { Email good, } \\
\text { skype ok, video } \\
\text { conference not } \\
\text { good }\end{array}$ & $\begin{array}{c}\text { Mostly used, } \\
\text { department co-located } \\
\text { at this point }\end{array}$ & $\begin{array}{l}\text { Use technology if } \\
\text { needed }\end{array}$ & $\begin{array}{l}\text { Understand technology will } \\
\text { be more used, however } \\
\text { cannot replace f-t-f. }\end{array}$ \\
\hline
\end{tabular}

Five of the participants are in a department that have all their members on one campus. This has naturally limited their use of computer-mediated meetings. These participants all experience a strong connection and trust to and with their co-workers. They do not believe that this will change when the next merger occurs, but they acknowledge that there is need for a period where new co-workers are allowed to get to know each other. However, the participants expect this to change when the merger settles. Then the department will have faculty on multiple campuses.

It is interesting to see that since VO1 already went through a merger in 2014 , there seems to be a little gap between the two already merged organizations. One participant from VO1 stated it was easier to conduct computer-mediated meetings before the first merger. The participant saw this as an irritation, due to the viewing computer-mediated meetings as more efficient and resource saving.

The findings indicate that there is a gap between the want to use communication technology to mediate meetings and the need. The participants recognize the geographical challenges eight campuses imply and understand the need to reduce travel among the campuses.

Further, it is interesting to see that there is an understanding of the need to use computer-mediated meeting structure more in the future. This seems to be independently from which original organization 
the participants came from, with the few exceptions. There is an anticipation in the new organization that there will be expectations to use more technology, to save money and resources on traveling to meet across campuses.

One participant, working within a very narrow field, pointed out that for him the internal communication through technology, other than email, would be limited also in the future. There would be no equivalent researchers located on other campuses also after the merger, all his collaboration partners were outside the organization or located on the same campus.

However, participants expressed a need to focus on employees' need to learn more about how to utilize the possibilities offered by the technology. One participant from $\mathrm{VO} 2$ pointed out how there is high focus on how to use technology to communicate with students and how to use technology in teaching settings, but how faculty and staff can use technology more efficiently to collaborate is not a focus that has been experienced within the organizations. The same participant also expresses a need for training for faculty and staff to learn the available technology for communication. Low computer literacy among faculty and staff may be a barrier of use in this transition.

\section{Discussion}

As discussed earlier, virtual teams, groups of dispersed individuals who rely on communication and information technologies are an important organizational form for supporting organizational activities that require the skills and knowledge of experts separated by distance and/or time [1]. This is supported by our findings, where faculty and staff from both VO1 and VO2 recognize the need to use communication technology when collaborating with new and existing co-workers in the future. The distances between campuses makes physical meetings inefficient and resource costly.

As we have seen from previous research, social identity is important as it defines how individuals perceive their own group, relative to others and other groups [6]. We see from our findings that there is a difference in shared identity between VO1 and VO2, which is supported by the quantitative data and interviews. The findings indicate that the previous merger for VO1 team members still plays a part in how much the employees feel like one unit. The quantitative findings for $\mathrm{H} 1 \mathrm{a}$ indicate a difference in perceptions of shared identity - with recently merged VO1 respondents perceiving a significantly lower level of shared identity than respondents from non- merged VO2. As it relates to their virtual interactions with their team members, a participant from VO1 shared that it was easier to conduct computermediated meetings before the merger. This corroborates the difference we see from the quantitative data, where shared identity is experienced differently in the two organizations.

The quantitative results for the other $\mathrm{H} 1$ constructs are likewise similar, with individuals who - due to the recent merger and subsequent change in their virtual team membership - must interact with a new set of team members, experiencing lower levels of team effectiveness and greater levels of interpersonal conflict and task conflict. The qualitative findings are likewise consistent with these results, and provide additional insight into how people differ in their experience and use of communication technology and computer-mediated meetings after a major merger and introduction of new virtual team members.

Key comments from interviewees during the qualitative data collection validated results from the quantitative findings regarding the difference between the organizations due to the merger. The comments indicate differences in concern that the new merged organization must be aware and ready to focus on how to get the different parts of the organization to work together and utilize communication technologies for better communication and collaboration, something not identified in the non-merged organization. As similarly noted in previous research, interviewees expressed concern that performance will suffer without interventions and reminders to members of virtual teams with new membership to ensure good and productive interactions [3-5]. As pointed out by the participants in both $\mathrm{VO} 1$ and $\mathrm{VO} 2$, there is a need for training to be able to utilize the technology for meetings across campuses. Without this kind of support, the use of technology for collaboration can be experienced as a barrier, which can discourage people from interacting and collaborating.

As noted in $\mathrm{H} 2$, no difference was found between members of virtual teams in either organization in regards to perceptions of leadership approach, purpose, and context. This reflects the relatively durable strength of cultural and professional influences on perceptions and behaviors. Although research has indicated the importance of these types of cultural and professional characteristics on minimizing differences and reducing outgroup perceptions when new members join a virtual team [11], we find that these characteristics may only be limited to certain relevant structural outcomes (e.g., team purpose and context) and not so relevant to 
minimizing perceptions of poor effectiveness and conflict. It may be that although common cultural characteristics can influence certain perceptions of the virtual team structure and context, it seems that these characteristics have less impact on perceptions that come about due to virtual team interactions (conflict and effectiveness). This result is also relevant given that we find through our qualitative analysis that the interactions taken by members of the virtual team often moved out of the virtual environment, further exacerbating feelings of disconnection and distance. We find that team members moving major decisions out of the virtual environment to be made in physical meetings can further create ingroup and outgroup distance, weakening the social identity of the virtual team.

These results have implications for theory and specifically the manner in which social information processing may influence the creating of social identity. Although SIP suggests that, the development of the group social identity would occur over time with the passage of adapted selectively perceived social information. It may be through the selective use of technology (or not) that the development of a social identity is hampered and even diminished. The choice of technology for certain types of communication may serve to further restrict and damage the development of social identity as individuals are excluded from certain types of critical or important communication. These changes in communication and may present indicators to virtual team members about their status in the group, and further strengthen assessments of outgroup placement. The informal meeting grounds before and after a meeting, in addition to the physical presence of co-workers, may create barriers to truly create virtual teams in the new organization, and serves to solidify differences in social identity between virtual team members.

\section{Limitations and future research}

This study presents the initial results of a longitudinal study using a mixed method approach. The presented research only describes the "as is" situation for the two university colleges after one of the organizations has experienced a merger, causing changes in the membership of the virtual teams in that organization. These two organizations themselves are in the process of merging, allowing a longitudinal view of the impact of prior experience and technology use on the development of the resultant organizations' virtual teams social identity. This ongoing merger will allow research to focus on how the organization will intervene and enable faculty and staff to become virtual teams working across campus and across departments while encouraging the development of a healthy social identity for these teams. The use of technology to create such teams and how faculty and staff experience computer-mediated communication and collaboration will provide unique insights to more deeply understand the manner in which technology use, virtual team experience, and even virtual team membership change experience will impact social identity development and perceptions of the virtual team context. In addition, in the future it will be interesting to explore the impact physical co-location have on the formation of social identity.

Although the differences in shared identity, team effectiveness, interpersonal conflict and task conflict are interesting topics to explore in future research, we acknowledge some limitations that can influence the results in this research. First, the change in virtual team membership occurred in the past and is not currently viewed or measured by the research. The perceptions and experiences collected now are likely influenced by past occurrences, but there is a possibility of some confounds that enter into the case that cannot be controlled. We are confident that our results reflect these changes alone. Through the use of different data collection methods with different respondents and interviewees, we feel that given the constructs that we found to be different and the constructs that we found to be similar, that our data is likely mostly influenced by the change in virtual team membership. However, we acknowledge the potential for other confounds. We anticipate our second round of data collection with the current change in organizations will corroborate our finding and provide deeper insights than our initial findings.

\section{Conclusion}

This is a very early stage of a longitudinal research, where we have indications of the current situation in two university college organizations that have and have not experienced a merger. It is important to take into account the political landscape of Norway, the governmental pressure to get the higher education entities to merge, and the Norwegian Model, where all employees have some power over their own working environment. Although, in this initial research we see two organizations that due to their nature should exhibit similar experiences to the use of communication technology within the organization, we find some differences between the two organizations, which can be explained by an earlier merger influence on virtual team membership. The difference in shared identity, team effectiveness, interpersonal conflict and task 
conflict, show that there might be challenges in the future creation of virtual teams across the eight campuses. Due to the initial nature of this research, the findings presented do not answer all the possible questions in this case. Nevertheless, it does create a good foundation for further research and gives us insight into aspects of virtual teams we may not have anticipated before.

\section{References}

[1]. Townsend, A.M., DeMarie, S.M., and Hendrickson, A.R. (1998) Virtual teams: Technology and workplace of the future. Academy of Management Executive. 12(3): p. 17-29.

[2]. Gilson, L.L., Maynard, M.T., Young, N.C.J., Vartiainen, M., and Hakonen, M. (2015) Virtual teams research: 10 years, 10 themes, and 10 opportunities. Journal of Management. 41(5): p. 1313-1337.

[3]. Bunderson, J.S., Van der Vegt, G.S., and Sparrowe, R.T. (2014) Status inertia and member replacement in roledifferentiated teams. Organization Science. 25(1): p. 57-72. [4]. Lewis, K., Belliveau, M., Herndon, B., and Keller, J. (2007) Group cognition, membership change, and performance: Investigating the benefits and detriments of collective knowledge. Organizational Behavior and Human Decision Processes. 103(2): p. 159-178.

[5]. Kuo, E.W. and Thompson, L.F. (2014) The influence of disposition and social ties on trust in new virtual teammates. Computers in Human Behavior. 37: p. 41-48.

[6]. Reicher, S., Spears, R., and Postmes, T. (1995). A social identity model of deindividuation phenomena. In W. Strobe and M. Hewstone (Eds.), European review of social psychology (Vol. 6). New York, NY: Taylor and Francis.

[7]. Taifel, H. and Turner, J.C. (1979). An integrative theory of intergroup conflict. In L.W. Austin and S. Worchel (Eds.), Psychology of intergroup relations (pp. 3347). Monterey, CA: Brooks and Cole.

[8]. Abele, A. and Petzold, P. (1996) Asymmetrical evaluation of ingroup versus outgroup members: A look from an information integration perspective. European Journal of Social Psychology. 26(2): p. 219-231.

[9]. Koomen, W. and Dijker, A.J. (1997) Ingroup and outgroup stereotypes and selective processing. European Journal of Social Psychology. 27(5): p. 589-601.

[10]. Jetten, J., Spears, R., and Manstead, A.S.R. (2001) Similarity as a source of differentiation: The role of group identification. European Journal of Social Psychology. 31(6): p. 621-640.

[11]. Gaertner, S.L. and Dovidio, J.F. (2000) Reducing intergroup bias: The common ingroup identity model, Philadelphia, PA: Psychology Press.

[12]. Walther, J.B. and Burgoon, J.K. (1992) Relational communication in computer-mediated interaction. Human Communication Research. 19(1): p. 50-88.

[13]. Walther, J.B. and Bunz, U. (2005) The rules of virtual groups: Trust, liking, and performance in computermediated communication. Journal of Communication. 55(4): p. 828-846.
[14]. Wakefield, R.L., Leidner, D.E., and Garrison, G. (2008) A model of conflict, leadership, and performance in virtual teams. Information Systems Research. 19(4): p. 434455.

[15]. Mortensen, M. and Hinds, P.J. (2001) Conflict and shared identity in geographically distributed teams. International Journal of Conflict Management. 12(3): p. 212-238.

[16]. Bazarova, N.N. and Walther, J.B. (2009) Attributions in virtual groups distances and behavioral variations in computer-mediated discussions. Small Group Research. 40(2): p. 138-162.

[17]. Crisp, R.J. and Beck, S.R. (2005) Reducing intergroup bias: The moderating role of ingroup identification. Group Processes \& Intergroup Relations. 8(2): p. 173-185.

[18]. Meld. St. 18 (2014-2015) (2015) Konsentrasjon for kvalitet. Strukturereform i universitets- og høyskolesektoren., Kunnskapsdepartementet: Oslo.

[19]. Ihlen, Ø. and Weltzien Hoivik, H. (2015) Ye olde csr: The historic roots of corporate social responsibility in norway. Journal of Business Ethics. 127(1): p. 109-120.

[20]. Creswell, J.W. (2013) Research design: Qualitative, quantitative, and mixed methods approaches: Sage publications.

[21]. Johnson, R.B. and Onwuegbuzie, A.J. (2004) Mixed methods research: A research paradigm whose time has come. Educational Researcher. 33(7): p. 14-26.

[22]. Pinsonneault, A. and Kraemer, K.L. (1993) Survey research methodology in management information systems: An assessment. Journal of Management Information Systems. 10(2): p. 75-105.

[23]. Pearce, C.L. and Conger, J.A. (2003). All those year ago: The historical underpinnings of shared leadership. Shared leadership: Reframing the hows and why of leadership (pp. 1-18). Thousand Oaks, CA: Sage.

[24]. Muethel, M., Gehrlein, S., and Hoegl, M. (2012) Socio-demographic factors and shared leadership behaviors in dispersed teams: Implications for human resource management. Human Resource Management. 51(4): p. 525-548.

[25]. Carson, J.B., Tesluk, P.E., and Marrone, J.A. (2007) Shared leadership in teams: An investigation of antecedent conditions and performance. Academy of Management Journal. 50(5): p. 1217-1234.

[26]. Hinds, P.J. and Mortensen, M. (2005) Understanding conflict in geographically distributed teams: The moderating effects of shared identity, shared context, and spontaneous communication. Organization Science. 16(3): p. 290-307.

[27]. Maynard, M.T., Mathieu, J.E., Rapp, T.L., and Gilson, L.L. (2012) Something(s) old and something(s) new: Modeling drivers of global virtual team effectiveness. Journal of Organizational Behavior. 33(3): p. 342-365.

[28]. Noy, C. (2008) Sampling knowledge: The hermeneutics of snowball sampling in qualitative research. International Journal of Social Research Methodology. 11(4): p. 327-344.

[29]. Patton, M.Q. (2002) Qualitative research \& evaluation methods. 3rd ed: SAGE Publications. 